\title{
FutureMe: Negotiating Learning Goals with your Future Learning-Self Avatar
}

\author{
Konstantinos Tsiakas \\ Eindhoven University of Technology \\ Eindhoven, Noord-Brabant, The \\ Netherlands \\ k.tsiakas@tue.nl \\ Danique Stappers \\ Eindhoven University of Technology \\ Eindhoven, Noord-Brabant, The \\ Netherlands \\ d.r.c.stappers@student.tue.nl
}

\author{
Deborah Cnossen \\ Eindhoven University of Technology \\ Eindhoven, Noord-Brabant, The \\ Netherlands \\ d.cnossen@student.tue.nl \\ Romain Toebosch \\ Eindhoven University of Technology \\ Eindhoven, Noord-Brabant, The \\ Netherlands \\ r.h.a.toebosch@student.tue.nl
}

\author{
Tim Muyrers \\ Eindhoven University of Technology \\ Eindhoven, Noord-Brabant, The \\ Netherlands \\ t.h.c.muyrers@student.tue.nl \\ Emilia Barakova \\ Eindhoven University of Technology \\ Eindhoven, Noord-Brabant, The \\ Netherlands \\ e.i.barakova@tue.nl
}

\begin{abstract}
This paper discusses the challenges towards designing an educational avatar which visualizes the future learning-self of the student in order to promote their self-regulated learning skills. More specifically, the avatar follows a negotiation-based interaction with the student during the goal-setting process of self-regulated learning. The goal of the avatar is to help the student get insights of their possible future leaning-selves, given a set of short-term goals regarding their study materials and homework. Our approach utilizes a recurrent neural network as the underlying prediction model for the future learning outcomes, in the context of language learning.
\end{abstract}

\section{CCS CONCEPTS}

- Human-centered computing $\rightarrow$ Interaction design process and methods; $\cdot$ Applied computing $\rightarrow$ Interactive learning environments.

\section{KEYWORDS}

educational avatars, self-regulated learning, future-self, language learning, student modeling

ACM Reference Format:

Konstantinos Tsiakas, Deborah Cnossen, Tim Muyrers, Danique Stappers, Romain Toebosch, and Emilia Barakova. 2021. FutureMe: Negotiating Learning Goals with your Future Learning-Self Avatar. In The 14th PErvasive Technologies Related to Assistive Environments Conference (PETRA 2021), June 29-July 2, 2021, Corfu, Greece. ACM, New York, NY, USA, 2 pages. https://doi.org/10.1145/3453892.3461008

\section{INTRODUCTION AND MOTIVATION}

Self-regulated learning (SRL) refers to the ability of students to control their own learning process. In the context of second language (L2) learning, research supports that successful language

Permission to make digital or hard copies of part or all of this work for personal or classroom use is granted without fee provided that copies are not made or distributed for profit or commercial advantage and that copies bear this notice and the full citation on the first page. Copyrights for third-party components of this work must be honored

For all other uses, contact the owner/author(s).

PETRA 2021, June 29-fuly 2, 2021, Corfu, Greece

(c) 2021 Copyright held by the owner/author(s).

ACM ISBN 978-1-4503-8792-7/21/06.

https://doi.org/10.1145/3453892.3461008 learners exhibit metacognitive and self-regulated learning skills which allow them to set goals for their learning, as well as to monitor, regulate, and control their cognition, motivation, and behavior [7]. Research studies have shown that SRL scaffolding and support can enhance learning and affective outcomes during language learning [4]. The second-language Motivational Self System has been used to investigate how language learners can get insights of their possible future selves in terms of learning outcomes [3], which can positively affect motivation and facilitate self-regulated learning. In the context of smoking cessation, the Future-Self Continuity model has been investigated to design avatars which visualize the future possible selves of the user based on their future actions [5]. Our research motivation is to test whether the interaction with a future language-learning self educational avatar can support student's metacognitive skills during goal setting and planning.

\section{PROPOSED APPROACH AND DISCUSSION}

Our proposed approach utilizes a recurrent neural network as the underlying prediction model of student's weekly progress considering the daily goals and learning outcomes. Recurrent neural networks (RNNs) are a variant of neural networks used to model sequential data and have been applied for student progress modeling. More specifically, RNNs have been used to predict final grades of university students from the log data stored in an online educational system [2]. Log data include information about learning activities that the student is asked to complete weekly, e.g., attendance, reports, quizzes, etc. These weekly activity data is used as a sequential input at the network in order to predict the final grade. Considering this approach, we will train a network that predicts the weekly learning outcome (e.g., weekly quiz grade) based on the daily time spent on each learning material.

We illustrate our approach in the context of language learning for children. The student interacts with the avatar during the goalsetting process of self-regulated learning. The goal of the interaction is to help the student set appropriate goals for the near future (e.g., weekly goals). More specifically, the avatar follows a negotiationbased approach [1] to provide the student with insights of their possible future learning-selves based on the time allocated daily for each language learning skill and study material (Vocabulary, 


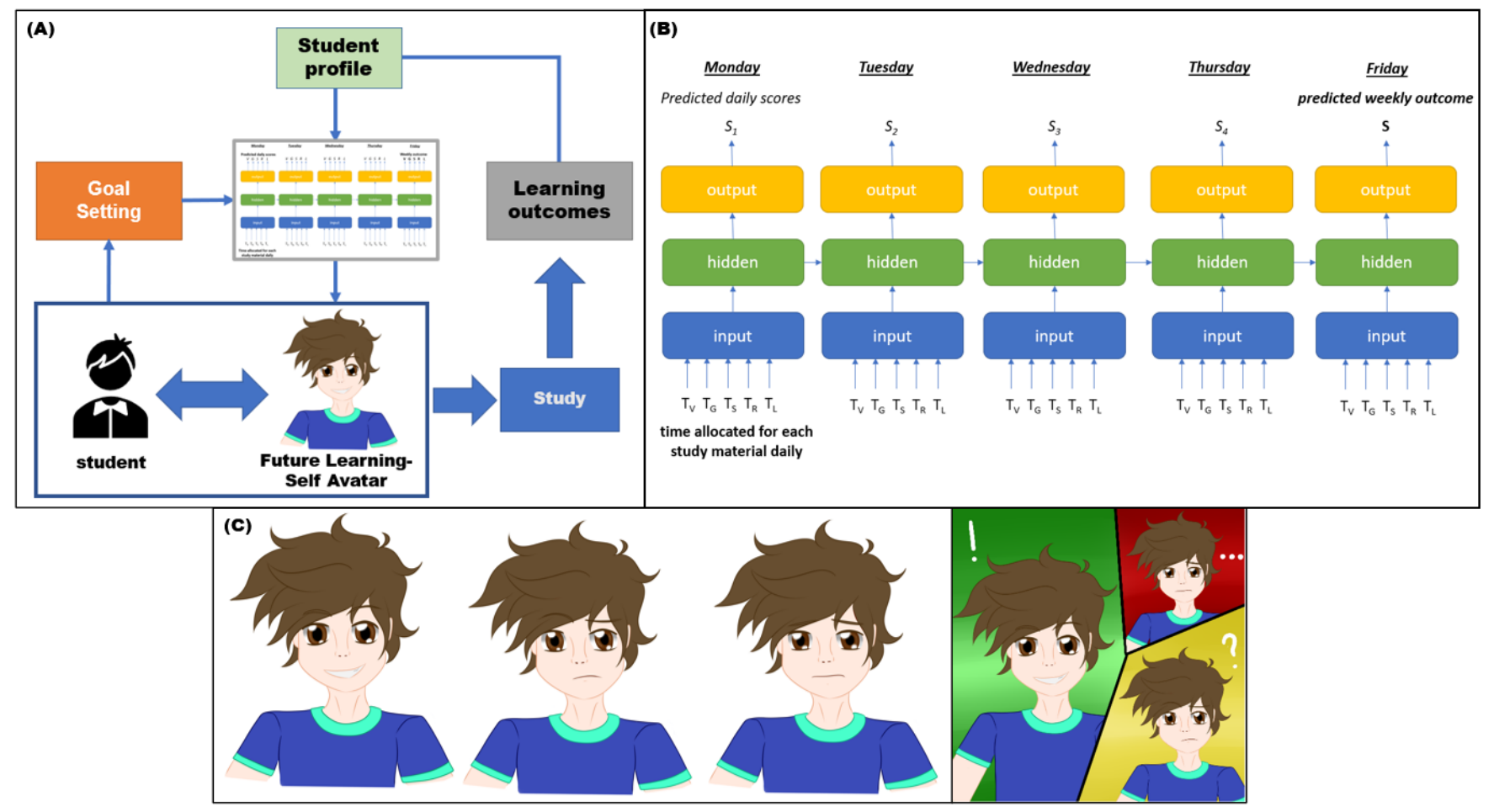

Figure 1: (A) Our proposed approach for a Future Learning-Self avatar. The student interacts with the avatar to set the learning goals for language learning. (B) The avatar utilizes an RNN to predict the learning outcomes for the specific individual (student profile). (C) The avatar follows a negotiation-based approach to help the student get insights about their long-term progress given their short-term choices. Multiple "possible" selves are displayed to depict the multiple possible learning goals and outcomes. Our goal is to investigate how different visualization (e.g., avatar expressions, background color) can be used to enhance student's motivation during the goal-setting process. Negotiations will be designed to provide the student with autonomy to make the final selection of their study plans.

Grammar, Speaking, Reading, and Listening), towards an efficient planning session.

The goal of the negotiations is to enhance student's motivation during the goal-setting process rather than automatically select the "correct" study plan and goals for the student. We will follow existing gamification guidelines and heuristics which are defined based on the Self-Determination Theory [6]. There will be two types of negotiations: (a) negotiate the feasibility of the indented goals (network sequential input) and (b) negotiate the outcome of the learning goals (network output). One of the main challenges of our proposed approach is that the avatar design should encapsulate the uncertainty of the student's input, e.g., when the student sets overly optimistic (or pessimistic) goals, as well as the model's prediction uncertainty. In order to tackle this, multiple future selves can be visualized, capturing the levels of uncertainty of the student's input (e.g., how likely it is to actually reach the given goals) and the prediction model's accuracy and confidence. Since the RNN predicts different learning outcomes for different sequence of goals, the negotiation aims to help the student understand that both their choices (goals) and actual actions (study) have consequences on their learning outcomes. Moreover, the design should elicit empathy, be easily understandable, and encourage the student to reflect on their goal-setting and experiment with different strategies. Our main research objective is to investigate the effects of the avatar to student's motivation and goal-setting skills through a longitudinal study.

\section{REFERENCES}

[1] Zhi-Hong Chen, Han-De Lu, and Chih-Yueh Chou. 2019. Using game-based negotiation mechanism to enhance students' goal setting and regulation. Computers \& Education 129 (2019), 71-81.

[2] Fumiya Okubo, Takayoshi Yamashita, Atsushi Shimada, and Hiroaki Ogata. 2017. A neural network approach for students' performance prediction. In Proceedings of the seventh international learning analytics \& knowledge conference. 598-599.

[3] Richard Sampson. 2012. The language-learning self, self-enhancement activities, and self perceptual change. Language Teaching Research 16, 3 (2012), 317-335.

[4] Thorsten Schodde, Laura Hoffmann, Sonja Stange, and Stefan Kopp. 2019. Adapt, Explain, Engage-A Study on How Social Robots Can Scaffold Second-language Learning of Children. ACM Transactions on Human-Robot Interaction (THRI) 9, 1 (2019), 1-27.

[5] Gizem Şenel and Mel Slater. 2020. Conversation with Your Future Self About Nicotine Dependence. In International Conference on Virtual Reality and Augmented Reality. Springer, 216-223.

[6] Rob van Roy and Bieke Zaman. 2017. Why gamification fails in education and how to make it successful: Introducing nine gamification heuristics based on selfdetermination theory. In Serious Games and edutainment applications. Springer, 485-509.

[7] Donglan Zhang and Lawrence Jun Zhang. 2019. Metacognition and self-regulated learning (SRL) in second/foreign language teaching. Second handbook of English language teaching (2019), 883-897. 